\title{
O Discurso sobre Deus na Pós-Modernidade
}

The Discourse on God in Postmodernity

Elias Gomes*

https://doi.org/10.29327/256659.12.2-18

SLOTERDIJK, Peter. Pós-Deus. Petrópolis: Vozes, 2019. 324 p.

Peter Sloterdijk está sendo atualmente considerado um pensador "original". No mundo acadêmico, subentende-se por originalidade aqueles pesquisadores que, supostamente, por convenção de seus pares - tiveram suas teorias ou ideias "imortalizadas". No que diz respeito ao respectivo livro, traduzido do original Alemão (NachGott) para língua portuguesa por Markus A. Hediger, publicado em 2019 pela Editora Vozes, é perceptivo que as áreas da teologia e da filosofia contemporâneas entram em jogo novamente, bem como questões de ordem política, que assiná-la os desenvolvimentos culturais e técnico-científicos imediatos.

Entretanto, embora o livro esteja listado entres os títulos mais recente publicados por Peter Sloterdijk, seus aportes teóricos e conteúdos mais expressivos não é de todo novo. Por exemplo, dos 12 capítulos contidos no livro, temos: manuscritos de palestras proferidas, prefácios, apresentações de pesquisas bem como capítulos de outros livros publicados anteriormente. Ainda sobre a configuração dos capítulos, em termos numéricos, 1 deles datam de mais de 20 anos; 3 são do final da década de 90 do século passado; 7 tem mais de 10 anos; sendo que, somente 1 de fato (capitulo 2) representa a data da publicação do livro em questão, mais precisamente em 2017.

No que diz respeitos aos aportes teóricos e conteúdos mais expressivos, destaca-se a descrição do fenômeno da globalização, começando por seus desenvolvimentos preliminares no final do século XX, cuja máxima repousa sobre as

`É Professor de Filosofia pela Secretaria da Educação do Estado de São Paulo (SEE/SP). EspecialistaemFilosofiaContemporânea (FACEL). MestreemCiência da Religião pela UniversidadeMetodista de São Paulo (UMESP). Atualmente o mesmodesenvolvepesquisasnasáreas de Filosofia, Educação e CulturaReligiosa. E-mail: filosofia.elias@hotmail.com. 
questões implicadas da afirmação ou do suposto reconhecimento da "morte de Deus". Nesse ponto específico, Peter Sloterdijk caracteriza Deus ou a ideia de Deus como "a maior fonte de cobertura de seguro". Tal afirmação, do ponto de vista histórico, tem em tese validado todas as religiões (pelo menos as monoteístas) supostamente "liberando" os possiveis paradoxos que tiveram consequências devastadoras desde a Idade Média até os temos modernos: o fundamentalismo triunfante é o seu pior experimento.

Proporcionalmente, o grande desafio filosófico do respectivo livro, está em tentar responder quais são os desenvolvimentos associados à frase visceral "Deus está morto", que reverbera desde, no mínimo, o final do século XIX? Isto é, seria ela apenas uma descrição de uma espécie de mudança de mentalidade? Seria ela uma representação contextual do que de fato aconteceu? Deve ela ser compreendida como um prognóstico que dá fim a todos os argumentos inter-religiosos?

O substrato temático extraído do livro, pode ser catalogado e didaticamente conduzidos, a partir dos principais assuntos, tais como: (1) A tautologia da metafísica tradicional e "morte" de Deus como reflexo consequencial; (2) A reforma protestante como estandarte de uma religiosidade da "negação" do mundo; (3) "Cosmologia" e religião; (4) A teologia do interior ou a espiritualidade subjetivada; (5) A ruptura Jesus ou bastardo de Deus; (6) Aprimoramento do ser humano; (7) Filosofia das neuroses; (8) A Latência do escondimento; (9) O imperativo místico; (10) O imperativos absolutos e categórico; (11) Novidades sobre a vontade de Crer; (12) O mundo religioso Willian James.

No que diz respeito a temática da tautologia da metafisica tradicional e entrelaçamento da "morte" de Deus como reflexo consequencial, Peter Sloterdijk apresenta a mesma, a partir do primeiro capítulo do livro intitulado: Crepúsculo dos deuses. De forma didática e, procurando fazer uma espécie de "analogia" entre filosofia e mitologia grega, nosso autor procura a pontar que o crepúsculo da civilização ocidental começa no instante em que os habitantes da grande construção cultural são tomados pelo pressentimento de que nem mesmo os sistemas humanos mais sólidos do presente foram de fato construídos para a eternidade (p. 9). Isto é, eles sempre estarão sujeitos a uma fragilidade inerente que é costumeiramente chamada também de "historicidade". Subintende-se, portanto que a historicidade significa para as civilizações o que a mortalidade significa para o indivíduo (p. 9-10). Na verdade, a imortalidade era a única característica dos deuses gregos; pois em geral no que dizia respeito à sua conduta, esta, com 
sua irônica humanidade demasiada, dificilmente poderia ter sido diferenciada do comportamento humano (p. 7).

Nesse sentido, a tautologia da metafísica supostamente estaria associada a filosofia da "morte" de Deus, justamente por causa do zelo suprematista, protagonizado pelos teólogos religiosos que por vezes insistiram em adornar seus Deus com os atributos mais brilhantes, tais como: onipotência e onisciência (p. 13-14). Para Sloterdijk, eles não levaram em consideração que, a proclamação simultânea desses atributos, desencadeiam uma contradição real de natureza altamente explosiva. Ele diz: [...] Ou Deus é todo-poderoso, caso em que sua vontade criativa permanece livre por todo o futuro e só pode ser espelhado por seu conhecimento apenas posteriormente; ou ele é onisciente, caso em que teria esgotado todo seu poder criativo; apenas assim ele poderia olhar para o universo do "ter sido" numa eterna happy hour (p. 14). Nesse ambiente, a premissa da "morte" de Deus é no minimo justificável.

Na segunda temática (a reforma protestante como estandarte de uma religiosidade moderna da "negação" do mundo) Sloterdijk, desenvolve o segundo capítulo de seu livro, o apontando para o fado de que após o processo histórico que desencadeou as reformas religiosas na Europa do século XVI, mais precisamente aquela protagonizada por Martim Lutero, passou a se defender, um "novo" modus operandi de uma espécie de religiosidade moderna e excêntrica capaz de estabelecer a "negação" do mundo (p. 41-42). Isto é, a tentativa argumentativa luterana que afirma o descrédito que a "meretriz razão", incentivada através do supervalorizado Aristóteles, defensor da tese segundo a qual o ser humano seria capaz, por esforços próprios, de desenvolver virtudes magnificas (p. 42). Mas, Lutero não quiz manter a mesma postura do contramundo monástico, pois o mesmo não servia para esclarecer a indisposição radical de sua existência (p. 47).

Assim, preferencialmente pautado no termo agostiniano peccatumoriginale[pecado orginal] Lutero teria então, "refutado" o elogio próprio de Deus no final de cada dia da criação. Na prática, após o pecado de Adão e Eva, ele via que na maioria das vezes, as coisas não eram boas e jamais eram valdebonum(p. 48). Para Sloterdijk, a reforma protestante é fruto de "desespero existencial" de seu principal protagonista, forjado a partir de uma antropologia negativa, incapaz de apostar numa analogia entis ou na teologia natural (p. 52-59). O lado positivo desse processo, repousa sob o paradoxo entre ação enérgica e a inatividade ex- 
trema; entrelaçando-se de um modo praticamente sem precedentes em termos de uma história das ideias da alma (p. 53).

Já a terceira e a quarta temática ("cosmologia" e religião e teologia do interior ou a espiritualidade subjetivada) é possivel apresentá-las como fenômenos intrinsecamente correlatos. Exemplificando: o ato de repulsa ou de "negação" do mundo, protagonizado por Lutero no século XVI, supostamente remeteria (por analogia) ao pensamento gnóstico do cristão primitivo, desencadeando assim, mais uma vez, a temática entre cosmologia e religião. Portanto, a irrupção de formas de pensamento gnóstico moderno se impõe sobretudo na história a partir dessa negatividade mundana (p. 74-75). Tal evidência, porém, não é meramente uma questão lógica. Sloterdijk afirma: [...] Dela depende o peso de autointerpretações mais elevadas da "existência" humana; sim, a própria "existência" não teria qualquer significado para nós, sem a revolução das relações de negação no espaço de um pensamento gnóstico e cristão primitivo (p. 75). Para heresia gnóstico moderna, a negação do "mundo" resulta do pavor dos poderes do mundo. Sloterdijk, defende de maneira emblemática, que desde de sempre, a vitrine em que as ruindades do mundo se expõem de forma espetacular é o poder político - na percepção das perspectivas daqueles que sofrem sua injustiça na forma de repressão e exploração (p. 77).

A grande ironia ou resultado subsequente de todo esse processo é sem dúvida, o que Sloterdijk vai chamar de "Pré-escola teológica à teoria do interior comum" (p. 103). Trata-se no reconhecimento de que, embora a religiosidade moderna seja de fato construída a partir da "negação" do mundo exterior em seus aspectos estrutural, cultural e político, tal ambiente ironicamente acabou por permitir e fomentar o desenvolvimento latente de um autoconhecimento do mundo interior. É como se Deus não ficasse "sem mundo". Isto é, o vidente infinito ou a visão máxima, se contrai em mim, num mínimo, e, age nesse sentido específico em mim (p. 136). Entretanto, a habitação de Deus em mim, não pode ser pensando como uma espécie de o gênio na garrafa; sua lógica é semelhante a uma transferência de oficio ou investidura, na qual os poderes oficiais são transferidos pelo senhor ao portador do oficio (p. 136). Assim, a essência desse ensinamento consiste no fato de que o meu "ser eu" assume um caráter oficial e minha subjetividade é concebida e autorizada como função de planejamento na economia de Deus. De maneira impressionante, a extensão não extensa de Deus, determina, portanto, em cada aspecto, o sentido de imanência ou de "ser em" (p. 136-137). 
Temos então a quinta temática. A chamada ruptura Jesus ou bastardo de Deus, é apontada por Sloterdijk, sobre aquela antiga tentativa de mais uma vez demonstrar que, embora a tradição cristã tem sempre procurado nos apresentar o Filho de Deus de maneira extremamente conservadora, na prática a realidade seria outro. Para o filósofo alemão, a identidade do Filho com o Pai não gera um contínuo genealógico, mas o rompe (p. 185). Na doutrina da encarnação, Deus gerou um filho ilegítimo com Maria. Portanto, a legitimação posterior, porém, desse filho transcendental só podia ser testificada por um esforço adicional (p. 185). Paradoxalmente, a fim de preservar a etiqueta, essa criança deveria ser criada num lar de um casal regular. Entretanto, uma mãe, capaz de ter um caso com o Verbo divino, e um pai, que aceitava isso, formam um casal não muito comum, contrariando na esfera da ação o modelo de "Família Sagrada" (p. 185). Porém, o que poderia ser tratado com uma espécie de "tragédia irreconciliável", acabou desencadeando um processo restaurador e motivacional para todos os filhos da cristandade. Isto é, quando o filho de todos dos filhos [Jesus Cristo ] conseguiu apresentar sua ilegitimidade evidente pela instrumentalidade de sua união com o Pai como uma forma superior de legitimidade, este, consequentemente, acabou acolhendo todos nós como "filhos ilegítimos" também, pois aonde as sementes voadoras do Espírito se espalham, tornam-se inimagináveis os frutos benéficos para as próximas gerações (p. 188-189).

O "aprimoramento do homem" e a "filosofia da neurose" podem ser pensados conjuntamente. No primeiro caso, a temática aparece no sexto capítulo do livro. Sloterdijk está convencido que os cidadãos do início da Modernidade foram convocados a se apresentar como especialistas de seu próprio sofrimento, prescrevendo -lhes o padrão da imitação de Cristo como caminhada ideal pela vida ( $\mathrm{p}$. 200-201). Porém, isso não deve ser entendido como uma espécie de programa de criatividade. Para o cristianismo, o ser humano não é interessante por ser esteticamente virulento. Não temos uma tendência natural de compor óperas ou de pintar pinturas. Teologicamente, o que vale para o "aprimoramento do homem" é que ele unicamente se torne semelhante a Cristo (p. 201). Ora, se olharmos para o projeto da "clonagem" de Cristo a partir daqui, percebemos o quanto já descemos para o nivel do pragmático, vivenciando a ineficiência de uma suposta antropotécnica (p. 202-203).

É justamente nesse tipo de ambiente que se costuma nascer as neuroses. A próxima temática (capítulo 7), demonstra que o sujeito neurótico é sem dúvida fruto do lema de uma sociedade iluminista pautada as custas da maioridade evo- 
cada por Immanuel Kant, que era definida como faculdade de se servir da própria razão sem o desempenho de outro - principalmente a tutela religiosa (p. 207). Isto é, sem a Reforma protestante, as ideais iluministas de liberdade e igualdade seriam sufocadas pelo medo e pela opressão da Igreja. Assim, a Revolução Francesa teria que esperar, e Igreja e o Estado absolutista continuaria. Em sua forma política mais elevando, a história da filosofia descreve o modelo de pensamento da transição da sociedade feudal para a sociedade burguês - ela formula a matriz daquele processo de emancipação que deveriam levar da dominação de pessoas para dominação de direito; da psicopolitica da ordem e da obediência para a psicopolítica da autoterminação de indivíduos iguais e livres (p. 207).

Consequentemente - no ponto de fuga da ideia de maioridade temos uma fantasia de autossuficiência radical e de desligamento definitivo da influência material e psíquica dos outros. O sentido da educação burguesa consiste em influenciar os indivíduos de tal forma que surja neles a ideia de que sempre teriam desejado a maioridade - independemente de qualquer influência (p. 208). Entretanto, a existência humana possui "necessidades especiais". A cultura nãoteológica da modernidade iluminista acabou tendo que se curvar diante da cultura da psicoterapia cuja máxima possui princípios inconscientes de religiosidade. Ele diz: [...] A psicanálise como prática individualizada do êxodo repete com cada cliente um esquema que, até hoje, marca a história do povo judeu. Cada paciente reproduz realmente um exodo privado mais ou menos discreto do Egito sob a liderança de psicoterapeutas que, normalmente, não admitirão que são sucessores mosaicos (p. 221).

Na continuidade, (Capítulo 8) Sloterdijk nos apresenta de maneira articulada a temática da Latência oculta no fenômeno do escondimento (p. 231). No respectivo capitulo, o autor procura estabelecer um diálogo com Heidegger. Segundo o mesmo, na perspectiva Heidegger, o processo que desencadeou o conhecimento tecnológico e científico era uma técnica de fazer o que é implícito, interno, escondido, seja explícito, isto é, trazê-lo ao descoberto (p. 232-233). A modernidade significa, nesse sentido, "explicar". Porém, a modernização não é a revolução, isso foi um mal-entendido, mas não no sentido lógico comum de explanar, e sim, no seu sentido cognitivo de trazer à superficie, ou seja, o jogo da linguagem central da atividade filosófica e, das ciências, consistia naquilo que seria o "justificar", "explicar" ou fornecer um motivo, a razão de algo (Begrïnden). Entretanto, a ironia está na revelação descobridora, através da qual tudo quanto seja racional e relativo é patenteado, não é ela própria racional nem relativa. O "espaço" do 
verdadeiro, enquanto não oculto, surge singularmente como uma ilha cheia de proporções comensuráveis, do oceano do incomensurável, do desproporcionado. O descoberto concebivel encontra-se no terreiro da lethe, do desmedido, do inconcebivel. Onde os homens estão, sempre o haverá um terreno avançado do monstruoso que está encoberto (p. 235-236).

Finalizando - é possivel perceber que nos últimos capítulos livro (9 á 12) a tentativa de o autor apresentar alguns aspectos que norteiam a religião ou religiosidade da chamada era pós-moderna. Trata-se em procurar compreende as "novidades" do mundo religioso (p. 276). Nesse sentido, começando pelo imperativo mistico, Sloterdijk vai dialogar como autores como SørenKierkegaard e Martin Buber. Ambos defendem uma religiosidade pautada numa experiência mística que transcendem os estatutos de uma religião institucionalizada. Em se tratando de Kierkegaard, a principal ideia de Sloterdijk, foi nos apresenta o suposto drama que o filósofo dinamarquês enfrentou ao ter que lutar, como sua própria existência, estabelecendo a diferenciação entre o gênio e o apostolo (p. 245-246). Sloterdijk diz: [...] não há dúvida de que as simpatias de Kierkegaard pertenciam ao tipo apostólico, no qual opera de forma irrestrita a seriedade do oficio doutrinal cristão - trata-se, porém, de simpatias que não consegue negar que Kierkegaard se via condenando a ser um gênio - um mero escritor que não sentia os plenos poderes do mandado apostólico (p. 246). Sobre Martim Buber, nosso autor, vai demonstrar que embora o editor das Confissões extáticas, fora a princípio, imaginado com um autor igualmente distante de todas as formas da religião teísta, seja ela judaica, muçulmana ou cristã; sobretudo na medida em que o mesmo vai utilizar de expressões aparentemente metarreligiosa da vivacidade psíquica; na prática, o que se percebe, é a presença de elementos distintivos de um imperativo místico latente (p. 247-248).

Entretanto, a pós-modernidade é cheia de contrastes. Embora podemos falar de suposto "reavivamento" da mística, a configuração de uma sociedade capitalista e globalizada, acabou concomitantemente formatando um tipo de imperativo categórico cuja máxima propõe um comportamento nocivo, não só para homem, mas sobretudo para o próprio planeta (p. 273). A palavra-chave nessa realidade mais recente é preocupação ecológica. Tal preocupação, existem prazos impostos por processos físicos externos - e ao contrário do que acontece na história humana, onde sempre podemos esperar uma segunda ou terceira chance para recuperar o que foi ignorado até então, nos processos ecológicos, domina uma espécie de lei da irreversibilidade (p. 272). 
Por fim, o conceito de Pós- Deus, precisa ser pensado a partir da secularização no sentido filosófico e ontológico do termo. Trata-se da absolutização do seculume a liquidação concomitante das duas grandezas transmundanas ou sobrenaturais não seculares: Deus e alma (p. 300). Com isso, nesse contexto - a segunda grandeza extramundana, a alma, perde seu fundamento na parceira com Deus. É necessário buscar salvação. Assim, citando Willian James, Sloterdijk, conclui: [...] para homem a chance de salvação é mais importante do que a própria salvação (p. 321).

Recebida em 02/05/2021 Aceita para publicação em 10/05/2021 